\title{
Enteric perforation of the gall bladder
}

\author{
V. K. SHUKLA \\ M.S.
}

M. KUMAR
M.S.

\author{
C. KHANDELWAL \\ M.B.B.S.
}

M. P. VAIDYA

F.R.C.S.(Edin. \& Eng.), F.A.M.S.

Department of Surgery, Institute of Medical Sciences, Banaras Hindu University, Varanasi-221005, India

\section{Summary}

A case of enteric perforation of the gall bladder in a 20-year-old male is reported. The patient recovered after cholecystostomy with closure of the perforation.

KEY WORDS: gall bladder, perforation, paratyphoid fever.

\section{Introduction}

Spontaneous perforation of the gall bladder due to acute calculous cholecystitis is not infrequent, but perforation in the absence of cholelithiasis is rare, the more so if it is of typhoid origin. The incidence in acute cholecystitis of free perforation into the peritoneal cavity with spreading or general peritonitis is about 3\% (Maingot, 1974). A case of enteric perforation of the gall bladder with peritonitis is the basis for this report.

\section{Case report}

A 20-year-old male was admitted complaining of severe abdominal pain and absolute constipation for $24 \mathrm{hr}$. He had also had fever for the last 3 weeks. Local examination revealed abdominal distension, muscle guarding and generalized abdominal tenderness. An abdominal radiograph in the erect position revealed multiple fluid levels. A provisional diagnosis of enteric perforation of the small bowel was entertained.

After resuscitation, the patient was explored by a right paramedian incision. The peritoneal cavity was found to be flooded with bile-stained fluid and a perforation about $7.5 \mathrm{~mm}$ in size was detected at the fundus of the gall bladder (Fig. 1). There was no calculus either in the gall bladder or the common bile duct. The perforation was closed and a cholecystostomy was performed. Culture of bile and peritoneal fluid grew Salmonella paratyphi A and Escherichia coli respectively. A Widal test showed a paratyphi A titre of $1: 180$ which was highly significant. Postoperative recovery was uneventful.

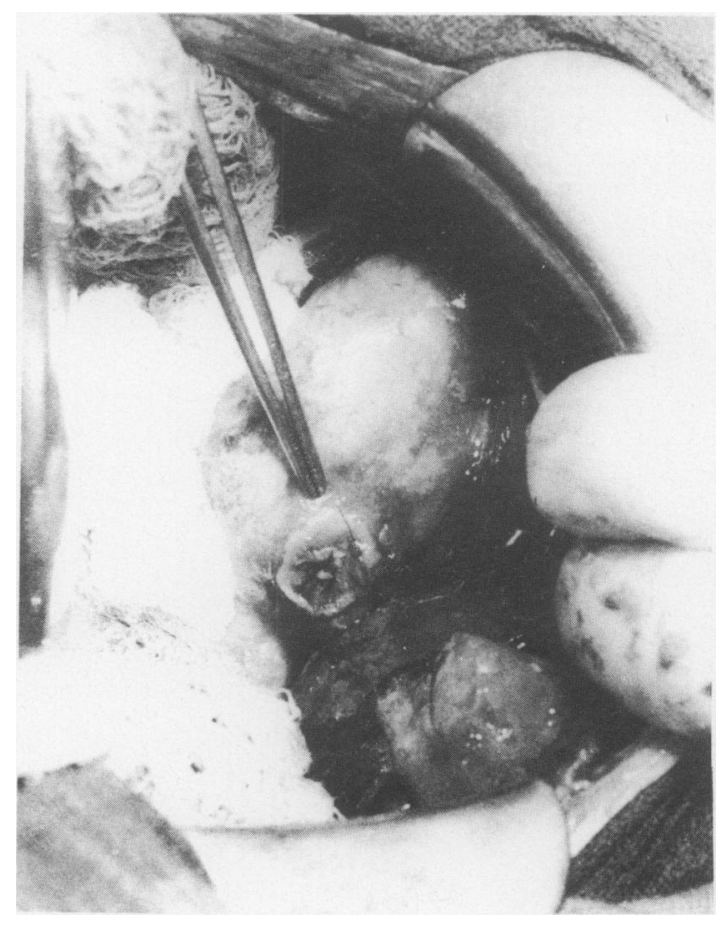

FIG. 1. Perforation at the fundus of the gall bladder.

\section{Discussion}

Perforation of the gall bladder was first reported 135 years ago by J. Duncan, a surgeon at the Royal Infirmary, Edinburgh (quoted by Gonsalves, 1979). 
Since then numerous cases of gall bladder perforation due to calculous cholecystitis have been recorded. Perforation occurred in $12 \%$ of 5600 cases of acute obstructive cholecystitis reported by Diffenbough, Saruer and Strohl (1949) while Friley (1972) reported an incidence of $7 \%$ in 2069 cases of acute obstructive cholecystitis. Similar figures for noncalculous cholecystitis are not available.

Neimeier (1934) categorized gall bladder perforation into 3 grades: Grade I-Acute free perforation; Grade II-Pericholecystic abscess formation; Grade III-Biliary fistula. Our case fell into Grade I. The overall mortality in this group is $53.3 \%$ (Gonsalves, 1979); the reason for this is the acute acalculous cholecystitis often associated with an acute infection such as pneumonia, typhoid fever or viral influenza (Gonsalves, 1979).

In $90 \%$ of acute cholecystitis cases, culture shows intestinal bacteria and in more than $50 \%$ of bile samples $E$. coli are present but streptococci, Salmo- nella paratyphi $\mathrm{B}$ and staphylococci are fairly cowmon. In our case, bile contained $S$. paratyphi A whịe the peritoneal fluid showed $E$. coli.

\section{Acknowledgment}

We are thankful to our Director, Professor J. Nagchaudhary, for his kind permission to publish the case.

\section{References}

Diffenbough, W.G., SARVer, F.E. \& STROHL, E.L. (1949) Gangrenous perforation of the gall bladder. Archives of Surgery, 59, 72. FRILEY, M. (1972) Perforation of the gall bladder. Review of Surg $8 y$, 29, 377.

GONSALVES, H.J.B. (1979) Spontaneous perforation of gall bladưfer due to acute non-calculous ulcerative cholecystitis. Journal of Royal College of Surgeons of Edinburgh, 24, 159.

NEIMEIER, O.W. (1934) Acute free perforation of the gall bladof. Archives of Surgery, 99, 922.

MAINGOT, R. (1974) Abdominal Operations 6th edn, I, p. $9 \overrightarrow{65}$ Appleton-Century-Crofts, New York.

(Accepted 14 May 1982) 